\title{
EL CIUDADANO-USUARIO DE LAS INFORMACIONES PÚBLICAS. EL CASO DE UNA EXOSMOSIS DOGMÁTICA EN EL ORDENAMIENTO CONSTITUCIONAL ITALIANO
}

Ph. D. Marta Cerioni Investigadora universitaria de Derecho público para la Universidad Politecnica delle Marche de Ancona (Italia). Doctorado en Derecho constitucional y Derecho público para la Universidad "Sapienza" de Roma (Italia), abogada. Correo electrónico: marta.cerioni@gmail.com

\section{Resumen}

En este ensayo se expone el tema de la relación entre las figuras de ciudadano y usuario, después de la introducción del Decreto-Legislativo $n^{\circ}$. 33/2013 en el ordenamiento italiano. Se inicia describiendo el estado actual, y se prosigue examinando los principios de democracia y transparencia. Tales principios han sido preordenados para entender de un modo diferente las relaciones entre administración y ciudadanos, que supera el tradiccional binomio "autoridad-libertad", y se polariza acerca del binomio "función-interés" (del ciudadano que disfruta del servicio). En consecuencia, el ciudadano llega a ser el usuario dotado de sólidas acciones y se genera el CNCU, como un órgano institucional cuyo parecer es obligatorio en la adopción de muchas actas.

Palabras clave: usuario, ciudadano, información pública, transparencia.

\section{Abstract}

This essay is about the relationship between the figures of citizen and user, after the introduction of the Legislative Decree $n^{\circ} 33 / 2013$ in the Italian system. After the description of it, we will go on analyzing the principles of democracy and transparence, as these are subject to a different way of understanding the relationship between administration and citizens, which goes over the traditional binomial "authorityfreedom", focusing instead the attention on the binomial "function-interest" (of the citizen user of the service). Consequently, the citizen becomes a user who is provided with strong actions to realize and also with an institutional authority: the CNCU, which opinion is essential for the adoption of several deeds. Finally, we will ask ourselves some critical questions about the results of the path we undertook.

Keywords: user, citizen, public information, transparence. 
Sumario: 1. El ciudadano y el usuario entre el "purismo teórico" y la "opacidad de la praxis"; 2. El ciudadano como titular del derecho al respecto de los principios democrático y de transparencia; 3. El usuario llega a ser el sujeto que ejercita los derechos de que el ciudadano es titular; 4. El primer efecto de la exosmosis: la responsabilidad política difundida y los feed-back para los usuarios; 5. El instrumentoganzúa del acceso cívico para volver efectivo un control difundido y constante de los ciudadanos-usuarios sobre política y P.A.; 6. El Consejo Nacional de los Consumidores y de los Usuarios elevado a parte institucional; 7. Una reflexiones críticas conclusivas sobre la democracia de los usuarios.

\section{El ciudadano y el usuario entre el "purismo teórico" y la "opacidad} de la praxis".

El ordenamiento jurídico italiano presenta, por lo menos en la teoría, la distinción entre las figuras de "ciudadano" y "usuario", la última emergida sólo recientemente. En la definición de ciudadanía, a pesar de las diferentes acepciones, se pueden identificar dos elementos fundamentales: uno es aquello relativo al "sometimiento", tendencialmente estable y permanente, a una autoridad estatal (la así llamada "sujeción"); y el otro, es relativo a la participación en una comunidad política organizada en un Estado; donde esta participación implica en principio el hecho de ser destinatarios de derechos y deberes que son diferentes con respecto a los de los estranjeros ${ }^{1}$.

* Traducción al castellano revisada por Dra. María José Cazorla González. Profesora Titular de Derecho civil. Universidad de Almería.

1 Para un examen de las teorías que consideran necesarios ambos estos elementos, se remite a MAKAROV, A., "Allgemeine Lehren des Staatsangehörigkeitsrechts", Stuttgart, 1962, pp. 21 s.; para las oportunas referencias a las diferentes teorías que consideran esencial sólo el así llamado status activae civitatis de nuevo a MAKAROV, A., "Allgemeine Lehren des Staatsangehörigkeitsrechts", Stuttgart, 1962, pp. 24 ss.; QUADRI, "Cittadinanza”, en NN.D.I., III, Torino, 1967, p. 315. En la literatura manuales de derecho constitucional se subraya a menudo como «la posición de ciudadano no se puede nunca agotar en una pura relación de sujeción»: así textualmente MORTATI, "Istituzioni di diritto pubblico", I, Padova, 1975, pp. 122 ss., y en términos similares MARTINES, "Diritto costituzionale", Milano, 1986, pp. 169 ss.; además, para una «sujeción permanente» que sea calificada por derechos políticos se refiere a VIRGA, "Diritto costituzionale", Palermo, 1979, pp. 39 ss.

Cfr. también CAPALOZZA, "La cittadinanza nell'odierno ordinamento giuridico", Torino, 1913; GEMMA, "L. 13-6-1912 sulla cittadinanza", Roma, 1913; MORAGLIA, "La Cittadinanza Italiana secondo la 1. 13-6-1912, n. 555", Forti, 1913; BUZZATI, "La legge sulla cittadinanza, 13-6-1912", Milano, 1914; DE DOMINICIS, "Commento alla legge sulla cittadinanza del 13-6-1912”, Torino, 1916; DEGNI, "Della cittadinanza", Napoli-Torino, 1921; BOSCO, "Nationalité en Italie", Répertoire de droit international publié par. A. De Lapradelle et J. P. Niboyet, t. IX, Paris, 1931, pp. 670 ss.; GATTESCHI, "Commentario delle leggi sulla cittadinanza", Bolzano, 1958; DOERNER, H., HECKER, H., "Das Staatsangehörigkeitsrecht Italiens (Sammlung geltender Staatsangehörigkeitsgesetze”, XXVIII, Frankfurt 
Según parte de la doctrina, la posición jurídica del usuario - entendido como él que disfruta de servicios estatales y paraestatales - puede ser reconducida a la de "ciudadano", con tal que éste sea «entendido como sujeto que vive de manera estable en alguna parte del territorio nacional y allí ha construido el centro de sus asuntos e intereses laborales, sin depender del hecho que tenga el status de "ciudadano", como se entiende tecnicamente, o sea según la acepción de ciudadanía política»².

Según esta formulación, la evolución del concepto de ciudadanía hacia una noción no técnica, pero más ajustada a la realidad, representa el resultado de la transformación de la compleja relación entre Estado (entendido como poder administrativo) y ciudadano, donde el ciudadano recubría la mera condición de «administrado» o hasta la de «súbdito», sometido a decisiones político-administrativas. Aquel modelo de administración y de Estado tenía como objetivo el interés público en virtud de que el interés del administrado podía ser sacrificable aún en su totalidad en calidad de «mero beneficiario pasivo de prestaciones». Piensen en las palabras pronunciadas por De Valles, en el discurso inaugural del año académico de la Universidad de Urbino, que tuvo lugar el 5 de noviembre de 1923, quien literalmente decía: «pues, al usuario, en la mayoría de los casos, le queda sólo la escasa consolación de la reclamación, que es seguramente la más popular en los institutos de control, en quanto cualquiera puede echarla: pero es el modo meno serio, porque la administración o no responde, o, cuando

am Main-Berlin, 1967; KOJANEC, "La cittadinanza italiana nei suoi riflessi interni ed internazionali", Roma, 1978; CLERICI, "Cittadinanza", NN.D.I. App., I, Torino, 1980, pp. 1265 ss.; BALLARINO, "Diritto internazionale privato", Padova, 1982, pp. 525 ss. y Appendice, 1983; BARIATTI, "Droit de la nationalité, Italie", Juris-Classeur. Nationalité. Commentaire des traités internationaux et des législations nationales, sous la direction de Ch. L. Closset et M. J. Verwilghen, Paris, 1983; ARENA, "La cittadinanza italiana. Nuova disciplina della cittadinanza dopo le pronunce della Corte Costituzionale e dopo l'entrata in vigore della 1. 21-4-1983, n. 123", Bologna, 1984; BALLARINO (a cura di), "Disposizioni in materia di cittadinanza", NLCC, 1984, pp. 969 ss.; PANETTA, "Commento alla nuova legge sulla cittadinanza", Rimini, 1984; PAGANO, "Commento alla 1. 13-6-1912, n. 555, sulla cittadinanza italiana", La legislazione civile annotata con la dottrina e la giurisprudenza a cura di Perlingieri, 1, Napoli, 1985; Id., "Commento alla 1. 21-4-1983, n. 123", ibidem, 2, Napoli, 1985; SACCHETTO, "La cittadinanza. Nuova problematica alla luce della 1. 21-4-1983, n. 123”, Milano, 1985; BAREL, “L. 15-5-1986, n. 180”, NLCC, 1986, pp. 1171.

${ }^{2}$ RINALDI, R., “La posizione giuridica soggettiva dell'utente di servizi pubblici”, Padova, 2011, pp. 2 ss. Sobre el usuario, cfr. CAMMELLI, M., "Per un nuovo statuto dell'utente", Pol. Dir., 1983; ALPA, G., "Contratti di utenza pubblica", Nuova giur. civ. comm., 1986; ARENA, G., "Valori costituzionali e ruolo della amministrazione", Studi in onore de V. Ottaviano, I, Milano, 1993; ID., "Proposte per una riforma della amministrazione", Pol. Dir., n. 3/1993; ID., "L'utente-sovrano”, Studi in onore di F. Benvenuti, Modena, 1996. 
responde, responde lo que quiere. Y el reclamante, satisfecho o no, tiene que darse por contento» ${ }^{3}$.

Además, la actividad administrativa del Estado continuó expandiendose también hacia unas "actividades sociales" según la célebre fórmula de V.E. Orlando ${ }^{4}$. Desde esta simple constatación, el ilustre jurista dedujo que «la idea de servicio no precede sino sigue la de la pública administración» ${ }^{5}$ y, prosiguiendo con el razonamiento, logró la consideración según la cual la entera actividad administrativa está vuelta al rendimiento de servicios públicos y, luego, estos no pueden ser considerados como categoría jurídica y figura jurídica verdadera, sino como fórmula sinóptica de los objetivos sociales de la administración. En esta perspectiva, la posición del usuario es identificable con la de un simple destinatario de la distribución de servicios por el Estado: él es simplemente «el punto final de la acción de otros - la Administración, justamente en la que él no participa excepto como destinatario y perceptor» ${ }^{6}$.

Como fue observado atentamente, las relaciones entre Administración y privados eran «menos aseguradas con respecto a las de ciudadanía, que bien existen. Este determina una especie de escisión, en el sujeto privado (persona), entre la posición de ciudadano y la de administrado, y, luego, una doble relación Estado/ciudadano, administración/administrado» ${ }^{7}$. En esta línea se encontraba la jurisprudencia anterior que, por lo menos hasta los años ochenta, consideraba que en los contratos predispuestos de manera unilateral por el sujeto público, el contrayente-usuario no tenía razón de temer la aplicación de cláusulas vejatorias, en cuanto el proceder de la pública

\footnotetext{
${ }^{3}$ DE VALLES, A., "I pubblici servizi e gli utenti. Verso nuove forme di esercizio". El texto ha sido reeditado, recientemente, como Relazioni dei rettori e discorsi inaugurali dei docenti nella libera università di Urbino, III (1917-1946), Arti grafiche editoriali, Urbino, 1997, pp. 1571 ss.

4 ORLANDO, V. E., "Introduzione al diritto amministrativo", Primo trattato completo di diritto amministrativo italiano, dirigido por V. E. Orlando, I, Milano, 1900, según el cual «la administración puede ser la actuación de la sovranidad del Estado, puede ser medio para lograr el objetivo de la tutela del derecho; y en tal caso esencialmente jurídico es el contenido. Pero, cuando la administración se aplica a la tutela económica, a la atención física de los individuos, a sus desarrollos intelectual, el supuesto de su actividad no es más el Estado, sino la sociedad que no es un organismo jurídico». (p. 275).

5 ORLANDO, V.E., "Primo trattato", óp. cit., pp. 58.

${ }^{6}$ ALLEGRETTI, U., “Amministrazione pubblica e Costituzione”, Padova, 1996, pp. 233 ss.

${ }^{7}$ RINALDI, R., “La posizione giuridica soggettiva dell'utente di servizi pubblici”, óp. cit., pp. 22. Similar a este es CASSESE, S., "Il cittadino e l'amministrazione pubblica”, Riv. trim. dir. pubbl., 1998, pp. 1018. Se aleja parcialmente la posición de G. Napolitano que cree que la relación de usuarios venga absorbida «en la más general relación de ciudadanía», (ID., "Regole e mercato nei servizi pubblici", Bologna, 2005, pp. 2).
} 
administración era, por definición, caraterizado de finalidad de interés general, y, luego, con valor intrínseco de imparcialidad y justicia ${ }^{8}$.

El viraje hacia esta fase está representado por la Carta Constitucional, y por la introducción de los principios personalista, solidario y de igualdad (art. 2 y 3 Const.) que han accedido a la mutación del punto de vista, llegando a una concepción según la cual la Administración tiene el deber de «servir a los hombres» ${ }^{9}$ como también imponía la orden del día de Dossetti ${ }^{10}$. En consecuencia, los servicios rendidos al ciudadanousuario tienen que ser entendidos como unos instrumentos para aumentar la autodeterminación, la libertad y, luego, «el lleno desarollo de la persona y la efectiva participación a la vida del País» ${ }^{11}$.

Para asistir a la mudada conciencia del «nuevo ciudadano» ${ }^{12}$, se esperó la entrada en nuestro ordenamiento jurídico de otras novedades legislativas, a partir de la Ley $\mathrm{n}^{\mathrm{o}}$ 241/1990, que introducieron el modelo de la administración participante en que el ciudadano es co-responsable de las acciones administrativas y, al mismo tiempo, "juez" de las mismas.

Por eso, se puede admitir que usuario y ciudadano son figuras que no coinciden por que se ajustan a relaciones diferentes. En este sentido, la ciudadanía es una relación estable y duradera con el Estado de pertenencia y que presupone unos requisitos muy precisos; al contrario de la relación de usuarios que es más relativa, porque se establece cada vez por medio de una elección (tal vez obligada) del mismo usuario. Por fin, no todos los ciudadanos son usuarios y no todos los usuarios son ciudadanos, aunque los últimos son normalmente usuarios también (especialmente de servicios públicos esenciales). Por eso, los dos conjuntos presentan una intersección allí donde el usuario es también un ciudadano, pero divergen por ejemplo en el caso que el usuario sea un estranjero regularmente permaneciente. De una parte, luego, la ciudadanía concierne la

\footnotetext{
8 BENEDETTI, A., "Profili evolutivi della tutela dell'utenza", Quaderni del pluralismo. Pubblicoprivato. I servizi pubblici, Torino, 1998, p. $288 \mathrm{~s}$.

${ }^{9}$ ALLEGRETTI, U., “Amministrazione pubblica”, óp. cit., p. 11.

10 Autos de la Comisión para la Constitución, primera subcomisión, 9 de septiembre de 1946, en http://legislature.camera.it/_dati/costituente/lavori/i_sottocommissione/sed003/sed003nc.pdf, $21 \mathrm{~s}$.

${ }^{11}$ Arena, G., "Proposte", óp. cit., p. 506. Sobre la institución al servicio de la libertad, cfr. SILVESTRI, G., "Intervento al Convegno Carceri, immigrazione, diritti umani nello spazio costituzionale europeo", que tuvo lugar el 15-16 de octubre de 2013 en la Università degli Studi "Roma Tre", disponible en www.radioradicale.it.
}

${ }^{12}$ BENVENUTI, F., "Il nuovo cittadino”, Venezia, 1994. 
relación hombre/Estado entendido como ente suministrator de servicios. El punto de conjunción entre las dos categorías es que los servicios públicos (en particular manera los esenciales) no se pueden reconducir tout court a meros contractos entre cives. El usuario es el consumidor de un servicio, mientras que el usuario de un servicio público es consumidor del servicio que el Estado, en calidad de entidad política, ha decidido de distribuir directamente, o porque se trata de un servicio connatural a la soberanía misma (por ejemplo justicia, orden pública, etc.) o porque se considera esencial a la existencia y desarollo de la persona humana (por ejemplo sanidad, educación, y así diciendo). Luego, si el usuario es el habitante del mercado, el usuario de los servicios públicos es un habitante exclusivo de aquel mercado, mejor dicho es el habitante para quien aquel mercado ha sido creado al fin de ser tutelado de manera mayor como persona y ciudadano $^{13}$.

Por estas motivaciones, hay conmixtiones muy frecuentes entre ciudadanía y usuarios y, aunque teoricamente distinguibles, a menudo concretamente confundibles.

\section{El ciudadano como titular del derecho al respecto de los principios} democrático y de transparencia.

Recientemente, el legislador ha hecho otro paso adelante, utilizando la palabra "usuario" también en el sentido de "ciudadano que tiene unos derechos de prestaciones positivas - incluso de natura genericamente política - hacia el Estado (instituciones electivas, Públicas Administraciones, y incluso partidos) aún accionables en juicio".

Piensen en la introducción del Decreto-Legislativo 14 de marzo de 2013, n 33, que lleva la "reordinación de la disciplina que concierne las obligaciones de publicidad, transparencia y difusión de informaciones de parte de las públicas administraciones", que de hecho ha oficializado la exosmosis en curso entre las dos figuras dogmaticas.

El objectivo de este texto normativo es lo de afirmar firmemente el principio de transparencia entendido como «llena accesibilidad de las informaciones que conciernen la organización y la actividad de las públicas administraciones, con la finalidad de favorecer formas difundidas de control sobre el perseguimiento de las funciones institucionales y sobre el utilizo de los recursos públicos» ${ }^{14}$.

\footnotetext{
${ }^{13}$ Sobre este punto, aconsentiréis en ser reexpedidos a mi reciente monografía, "Diritti dei consumatori e degli utenti”, Napoli, 2014 y allí amplia biograf ía citada.

${ }^{14}$ Art. 1, apartado 1 del d.lgs. n. 33/2013.
} 
Más precisamente, la transparencia se indica como un instrumento que contribuye a «realizar el principio democrático y los principios constitucionales de igualdad, imparcialidad, buena marcha, responsabilidad, eficacia y eficiencia en el utilizo de los recursos públicos, integridad y lealtad en el servicio a la nación. Esta es condición de garantía de las libertades individuales y colectivas, y además de los derechos civiles, políticos y sociales, integra el derecho de una buena administración y contribuye a la realización de una administración abierta, al servicio del ciudadano» ${ }^{15}$.

En una perspectiva que se orienta hacia la constitución, el derecho al conocimiento de las acciones de los poderes públicos de parte de los ciudadanos corolario del principio general de transparencia que valoriza la posición constitucional del ciudadano en el Estado de democracia pluralista - representa la emersión de un "nuevo derecho"16.

Los principios mencionados, al servicio de los cuales está la transparencia, aclaran de manera punctual como el problema central de las democracias contemporáneas se encuentra en la circulación de las informaciones, ya que es proprio a través de la «transparencia de las decisiones che consigue de tal circulación» que es posible medir la «realización del principio de soberanía popular» ${ }^{17}$.

Empezando por los arcana imperii de memoria tacitiana ${ }^{18}$, en las diferentes formas de Estado que se han sucedido, el principio de secreto de las acciones públicas y de las decisiones política ha sido siempre un imperativo conectado al ejercicio de los poderes públicos.

\footnotetext{
${ }^{15}$ Art. 1, apartado 2, d.lgs. n. 33/2013.

${ }^{16}$ COLAPIETRO, C., "Trasparenza e democrazia: conoscenza e/è potere”, L. Califano , C. Colapietro (a cura di), "Le nuove frontiere della trasparenza nella dimensione costituzionale", Napoli, 2014, p. 17.

${ }^{17}$ CHELI, E., "Informazione, decisione politica, controllo sociale: spunti per un'analisi comparata", Dir. inf., 1987, p. 813, que encuentra en la existencia de las deomocracias contemporáneas un complejo entrelazamiento de flujos informativos que se vinculan «tanto a la actividad conoscitiva del Estado, cuanto a la actividad informativa del Estado y sobre el Estado, los cuales condicionan tanto a la decisión política cuanto al control social».
}

${ }^{18}$ La locución se debe a la obra de TACITO, P.C., "Annali", libro II, 36, que define como arcana imperii la astuta política de Tiberio, y luego ha sido retomada, antes por CHAPMAR, A., "De arcanis rerum publicarum libri", VI, Bremen 1605, para elaborar una teoría general del arcano (distinguendo entre arcana imperii y arcanum dominationis) y después por SCHMITT, C., "La dittatura. Dalle origini dell'idea moderna di sovranità alla lotta di classe proletaria" (1921), Roma-Bari 1975, pp. 26 ss. (cfr. CORSO, G., "Potere politico e segreto", AA.VV., "La trasparenza amministrativa", a cura di F. Merloni, Milano 2008, 278). 
El secreto ha sido concebido como función instrumental a la acción unilateral de la Pública administración ${ }^{19}$ y a la ímagen muy limitativa de la administración, que se consideraba llamada «para actuar las elecciones hecha por el legislador» ${ }^{20}$, no conscientes que en el Estado contemporáneo la P.A. no es más sólo mera ejecución, sino también se ha vuelto sobre todo en ser gestión, con amplios margenes de elecciones discrecionales $^{21}$ : «no cumple, sino interpreta, elige, decide», practicando «un poder ampliamente autónomo y siempre más dificilmente controlable con los instrumentos tradicionales» ${ }^{22}$.

De hecho, en la concepción clásica la relación entre administración y ciudadanos se expresaba en el binomio "autoridad-libertad" sobre la base de la argumentación que sólo por medio «del ejercicio de autoridad, la administración puede realizar [...] los objetivos que la ley le ha dejado» ${ }^{23}$. Asì, durante siglos «el Estado y el derecho público han sido dominados por el conflicto Estado-ciudadano, dos polos irreducibles y en contraste entre ellos [...] por causa de la superioridad de uno sobre el otro ${ }^{24}$, que ha hecho que nuestra administración, como la de muchos paises europeos, se desarrollara sobre la base de aquel paradigma bipolar fundamental teorizado por Santi Romano» ${ }^{25}$, en el ámbito de que administración y ciudadanos constituyen dos polos «de una relación asimétrica, conflictual, fundada en la separación y la discrepancia de los intereses ${ }^{26} \gg$.

19 Cfr. a propósito MARINO, I.M., "Giudice amministrativo, motivazione degli atti e «potere» dell'amministrazione”, Foro. amm. Tar, 2003, p. 360.

${ }^{20}$ OROFINO, A.G., "Profili giuridici della trasparenza amministrativa", Bari 2013, p. 17, a que se remite para una atenta análisis de los profilos evolutivos del principio de transparencia

${ }^{21}$ Sobre este punto cfr. COLAPIETRO, C., "Governo e amministrazione. I: La dirigenza pubblica tra imparzialità ed indirizzo politico”, Torino 2004, espec. pp. 1 e 13.

22 ARENA, G., "Trasparenza amministrativa e democrazia", en AA.VV., "Gli istituti di democrazia amministrativa", a cura di G. Berti e G.C. De Martin, Milano 1996, p. 16.

23 BONOMO, A., "Informazione e pubbliche amministrazioni. Dall'accesso ai documenti alla disponibilità delle informazioni”, Bari, 2012, p. 52.

${ }^{24}$ CASSESE, S., “L'arena pubblica. Nuovi paradigmi per lo Stato”, Riv. trim. dir. pubbl., 2001, pp. 602 ss., según quien este representa «el paradigma fundamental del derecho público en el XX siglo», y ha sido fundado sobre la separación entra Estado y comunidad. Entre autoridad y libertad, sugún la enseñanza de GIANNINI, M.S., "Lezioni di diritto amministrativo", Milano 1950, p. 71.

${ }^{25}$ Cfr. ROMANO, S., "Corso di diritto amministrativo", Padova 1930, 83, que distinguía entre «sujetos activos y pasivos de la potestad administrativa», contraponendo, «de un lado, los sujetos que administran y que, en su conjunto, constituyen [...] la pública administración, y, de otro lado, los administrados».

26 ARENA, G., "Trasparenza amministrativa", AA.VV., "Dizionario di diritto pubblico", a cura di S. Cassese, vol. VI, Milano 2006, p. 5953. 
Por otro lado, ha sido evidenciado como aún la Constitución del 1948 propendía a una visión "estática" de la posición constitucional del ciudadano con respecto a los poderes públicos, en el ámbito de la cual no era posible que «la más amplia puesta a disposición de las informaciones poseídas pudiera llegar a ser una actividad obligatoria para los sujetos públicos», a que hacer corresponder «un preciso derecho de obtener aquellas informaciones» ${ }^{27}$.

Con la entrada en vigencia de la Constitución italiana, de otro lado, la transparencia ha divenido una obligación para la Administración, impuesta propio por el principio democrático.

Ya que la única acción verdaderamente incisiva que el ciudadano podía realizar era el derecho de votar, es evidente que para ejercitarlo de manera correcta era necesario tener todas las informaciones disponibles al fin de promover aquella noción de democracia como «poder en público» tal de «indicar todos los expedientes institucionales que obligan a los gobernantes a tomar sus decisiones a la luz del día y permiten a los gobernatos de "ver" como y donde las toman» ${ }^{28}$.

Por eso, antes se ha pasado por el inicial acto de teorizar abstractamente el derecho a la información, que como el precedente estadounidense de Freedom of Information Act de 1996 reconoce el derecho difundido a acceder a documentos administrativos no necesariamente conectados a una específica legitimación derivante de un dimostrable interés al acceso, para después adherir a una concepción, si se puede decir, continental del derecho de acceso, implantado en Italia siguiendo los ejemplos de Francia y de España, llegando a prefigurar antes con el DLeg 27 de octubre de 2009, $\mathrm{n}^{\circ} 150$, y a afirmar al final con el Dleg 14 de marzo de 2013, $n^{\circ} 33$, un modelo de accesibilidad total.

Un anclaje aún más sólido ha sido delineado por el Tribunal Constitucional que ha localizado, en el primer apartado del art. 97, el fundamento de la publicidad y de la transparencia, y en particular en el principio della buena marcha. Sin embargo, tenemos que remarcar como, aún en la jurisprudencia constitucional, no falten unas oscilaciones

\footnotetext{
${ }^{27}$ MARSOCCI, P., "Gli obblighi di diffusione delle informazioni e il d. lgs. 33/2013 nell'interpretazione del modello costituzionale", Ist. fed., 2013, p. 692.

${ }^{28}$ BOBBIO, N., "La democrazia", en ID., "Teoria generale della politica", a cura di M. BOVERO, Torino 1999 , p. 339.
} 
conciernentes la relativa calificación de los dos institutos ${ }^{29}$, que han sido definidos a veces como «objetivos» que derivan de sus natura ontológica de «valores esenciales en un ordenamiento democrático ${ }^{30}$, o bien como «criterios» ${ }^{31} \mathrm{o}$, de nuevo, como «principios constitucionales» ${ }^{32}$ o incluso «con cobertura constitucional» ${ }^{33}$, anclada a los «principios del patrimonio común de los paises europeos» ${ }^{34}$.

Por eso, propio basandonos sobre la íntima relación entre transparencia y democracia, se pueden suponer «nuevas formas de ejercicio de la soberanía popular y, luego, de tutela de la dignidad de la persona» ${ }^{35}$ y observar el ciudadano en frente a los nuevos horizontes del Estado y del mercado.

\section{El usuario llega a ser el sujeto que ejercita los derechos de que el} ciudadano es titular

Es obvio que la nueva concepción de transparencia presupone un diferente modo de entender las relaciones entre administración y ciudadanos que sobrepase el tradicional binomio "autoridad-libertad", polarizandose alrededor del binomio "funcióninterés" (función de la administración y del interés del ciudadano que disfruta del servicio $)^{36}$. Este tiene que ser entendido en el sentido que «no hay la pareja "podersumisión" que caracteriza el actuar administrativo, sino la pareja "función socialderechos de la persona" ${ }^{37}$.

El principio de transparencia, de hecho, se entiende con el principio democrático, porque en las actuales democracias representativas - fundadas en la necesaria distinción

\footnotetext{
${ }^{29}$ Como exhaustivamente ha subrayado MARSOCCI, P., "Gli obblighi di diffusione delle informazioni e il d.lgs. 33/2013 nell'interpretazione del modello costituzionale di amministrazione", en Ist. fed., 2013, pp. 699 ss.

${ }^{30}$ Esta definición ha aparecido por primera vez en Corte cost., sent. n. 262/1997, en www.giurcost.it.

${ }^{31}$ Corte cost., sent. n. 104/2006, en www.giurcost.it.

${ }^{32}$ Corte cost., sent. n. 372/2004, en www.giurcost.it.

${ }^{33}$ Corte cost., sent. n. 175/2011, en www.giurcost.it.

${ }^{34}$ Corte cost., sent. n. 104/2006, en www.giurcost.it.

35 ARENA, G., "Trasparenza amministrativa e democrazia", AA.VV., "Gli istituti di democrazia amministrativa”, a cura di G. Berti e G. C. De Martin, Milano 1996, pp. 13 ss.

36 ARENA, G., "L' «utente-sovrano»", en AA.VV., "Studi in onore di Feliciano Benvenuti", vol. I, Modena 1996, 156. ARENA, G., "Trasparenza amministrativa e democrazia”, óp. cit., p. 22 s.

${ }^{37}$ ALLEGRETTI, U., "Pubblica amministrazione e ordinamento democratico", en Foro it., n. 5/1984, p. 17.
} 
entre pueblo, como «sujeto permanentemente poseedor de la soberanía» y las instituciones, o sea, «sujeto momentáneamente ejerciente de la soberanía» - propio el principio de transparencia «rige el sistema total, tanto en la fase (ascendente) de delegación y legitimación al ejercicio del poder, como en el tiempo (descendiente) de control de las formas y del resultados de dicho ejercicio» ${ }^{38}$.

El sistema viene ocupado por el concepto detonante de que existe un ciudadanousuario al que la administración tiene que satisfacer, no sólo en base a los cánones constitucionales o, mejor dicho, de manera imparcial y eficiente, sino también lógicas de empresa y económicas que en necesario tienen que darse cuenta de la satisfación del usuario $^{39}$.

\section{El primer efecto de la exosmosis: la responsabilidad política} difundida y los feed-back para los usuarios.

Las relaciones causa y efecto, en el sector administrativo y político, han sido las siguientes. Para que el ciudadano pueda juzgar correctamente a sus gobernantes y a la administración, él necesita de informaciones completas que tienen también la finalidad de instaurar un régimen completamente democrático. Por eso, es necesario prohibir para siempre el secreto y «donde un superior, interés público no impone un secreto momentaneo, la casa de la Administración tendría que ser de cristal» ${ }^{40}$. Sólo de esta manera, será posible crear un sistema de control difundido sobre las acciones de los organismos electivos y de las P.A.

Un ulterior ejemplo, fue confirmado por la adocción del decreto ley 28 de diciembre de 2013, nº149 sobre la "abolición de la financiación pública directa,

\footnotetext{
${ }^{38}$ DONATI, D., "Il principio di trasparenza in Costituzione", AA.VV., "La trasparenza amministrativa", a cura di F. Merloni, Milano 2008, p. 129, que, recorriendo otra vez la función tenida por el principio de transparencia en la evolución de los Estados liberales y democráticos, detecta que este principio ha representado antes el valor-guía tanto en la configuración de la organización «racional» (o sea según lógicas visibile y intelegibles) de los poderes público, siendo instrumento fundamental «para la comprensión y la valutación del ejercicio del poder en su diferentes formas», como en la constitucionalización (con las relativas garantías) de las así dichas libertades del Estado, como instrumento «de la afirmación y del conocimiento de los derechos»; en una segunda fase, en cambio, la transparencia ha concurrido al ampliamento y a la consolidación de aquellos derechos a la participación política (las así dichas libertades en el Estado) que marcan el pasaje al modelo democrático, como instrumento «para la participación consciente a la formación de las elecciones políticas».

${ }^{39}$ MARGHERI, A., "La rilevazione della customer satisfaction nelle amministrazioni pubbliche", en Informator, 2009, pp. 9 ss.

${ }^{40}$ TURATI, F., "Atti del Parlamento italiano, Camera dei deputati”, sess. 1904-1908, seduta del 17 giugno 1908, p. 22962.
} 
disposición para la transparencia y la democraticidad de los partidos y disciplina de la contribución voluntaria y de la contribución indirecta para ellos", convertido en ley con modificaciones a la Ley n ${ }^{\circ} 13$ del 2014.

En el preámbulo, tenemos la causas sociales que originaron esta providencia individuadas en la contención del gasto público y en el malestar de los ciudadanos por el empleo demasiado disinhibido de los recursos públicos en un momento de grave situación económica del País ${ }^{41}$.

En modo más significativo, el Decreto considera relevante «además la ineludible exigencia de asegurar el pasaje a un sistema fundado en la libre elección de los contribuyentes, que attribuye a los ciudadanos una función central en la financiación de los partidos, esperando sus naturas de asociaciones constituidas para concurrir con método democrático en determinar las políticas nacionales, conforme al árticulo 49 de la Constitución».

En este pasaje se puede advertir como en el circuito ciudadanía-partidos políticosrepresentancia electoral entran los "contribuyentes" también, entendidos como los que pagan para un determinado servicio, o sea, de los usuarios finales con los que la política tiene que confrontarse, en particular modo a través de mecanismos de feed-back que aseguren a estos que el servicio ha sido prestado bajo el standard de calidad y eficiencia. En este caso, se debe entender el que no se hayan verificado derroches y corrupción por parte de la política con la finalidad de relevante «favorecer formas difundidas de control sobre el cumplimento de las funciones institucionales y sobre el utilizo de los recursos públicos» (art. 1, apartado 1, Dleg 33/2013).

El ciudadano-usuario, en una democracia que quiere ser efectiva y controlada de manera continua por quien representa la soberanía popular, aspira a llegar a ser juez del proceder de las administraciones y de la política. La fase actual de grave crisis económico-financiera hace que este aspecto se cangrene, a menudo excediendo con las pretensiones a través de formas de populismos también violentas.

Constitucionalmente, hay una ampliación de la esfera que pertenece a la responsabilidad política como species de responsabilidad que no pertenece al género de la responsabilidad jurídica. La responsabilidad política, de hecho, se puede hacer respetar según situaciones no tipificadas (y no tipificables), ya que no existen criterios

\footnotetext{
41 «Ya que la grave situación económica del País impone con urgencia la adopción de medidas que intervengan en el gasto público, en linea con las expectativas de los ciudadanos de superación del sistema de la financiación pública de los partidos y en coerencia con la linea de austeridad y de rigor de la política de balance adoptada en los ultimos años».
} 
de evaluación de los comportamientos referidos a los responsables, ya que falta «la comunicación predeterminada de las normas entre (nombrado y específico) hecho y una (nombrada y específica) consecuencia» ${ }^{42}$.

\section{El instrumento-ganzúa del acceso cívico para volver efectivo un} control difundido y constante de los ciudadanos-usuarios sobre política y P.A.

Además, el nivel de calidad de las informaciones establecidas por el Estado no puede ser derogado en peor, porque representa la individualización del nivel esencial de las prestaciones suministradas por las Administraciones públicas con finalidad de transparencia, prevención, contraste a la corrupción y a la mala administración, conforme al árticulo 117, segundo apartado, letra m, Const. De hecho, propio en la ley, la transparencia se concibe como valor que funda toda la Pública Administración, que tiene que ser "al servicio del ciudadano".

En consecuencia, toda la Ley pone una tupida malla de normas, las cuales hacen que los deberes de la Pública Administración sean más apremiantes y al mismo tiempo transparentes.

Un caso ejemplificativo se puede representar con la institución del acceso cívico. El legislador italiano ha modificado la perspectiva del derecho de acceso; al acceso procedimental clásico de que los árticulos 22 y siguientes, Ley no 241 de 1990, necesariamente conectado a las específicas exigencias del solicitante (need to know) se ha añadido el así dicho acceso cívico -imitando al ejemplo de los ordinamientos anglosajones $^{43}$ y de específicos sectores del ordenamiento ${ }^{44}$ - que garantiza a la entera colectividad el derecho de conocer los actos adoptados por la públicas administraciónes en función de control generalizado por parte de la opinión pública y de llena realización del principio de transparencia (right to know).

El acceso cívico puede ser accionado por cualquiera, sin motivación y es gratuito, y se diferencia del acceso procedimental, que puede ser pedido sólo por quien tiene una posición diferenciada, motivandolo y pagando los derechos de secretaría y las copias. Sin embrago, el acceso cívico es un instrumento ulterior también por los que pueden ejercitar el acceso tout court.

\footnotetext{
${ }^{42}$ RESCIGNO, G. U., “Responsabilità (diritto costituzionale)”, en Enc. dir., Milano 1988, p. 1342.

${ }^{43}$ Se vea el Freedom of Information Act, así dicho FOIA estadounidense.

${ }^{44}$ Para la materia ambiental, v. la Convención de Aarhus, recibida con L. n. 195 del 2005.
} 
Por otra parte, el acceso tradicional, de que se habla en la Ley nº 241 del 1990, continua con su diferentes presuposiciones y disciplina, pero la circunstancia que un sujeto pueda ser titular de una posición diferenciada que se tutela con esta tipologia de acceso, non le impide al mismo sujeto valerse del acceso cívico, en el caso de que se presentaran las presuposiciones. Para los actos comprendidos en las obligaciones de publicación de que se habla al Dleg $\mathrm{n}^{\circ} 33$ de 2013, luego, podrán obrar de modo acumulativo tanto el derecho de acceso "clásico" ex Ley No 241 de 1990, como el derecho de acceso cívico ex Dleg n³3 de 2013, mientras, para los actos que no forman parte en estas obligaciones de publicación, sólo obrará el derecho de acceso procedimental "clásico".

«Razonando diferentemente, se llegaría al resultado que el ciudadano sin interés específico podría recurrir al acceso cívico, mientras el sujeto portador de interés específico tendría que demostrar las más convincentes presuposiciones subtendida al interés procedimental de tipología tradicional (árt. 22 Ley n ${ }^{\circ} 241$ de 1990)» ${ }^{45}$.

En consecuencia, la transparencia se une al circuito soberanía-representación y, por ende, a la categoría dogmática del ciudadano.

\section{El Consejo Nacional de los Consumidores y de los Usuarios elevado a} parte institucional.

El salto lógico hacia con la figura del usuario llega al art. 10 del mismo Decreto, en el caso de que obliga a las P.A. a adoptar el programa trienal para la transparencia y la integridad, consultado el parecer del Consejo nacional de los consumidores y de los usuarios.

Ante todo, se debe clarificar que el Consejo Nacional de los Consumidores y de los Usuarios (CNCU) es el organo representativo de las asociaciones de los consumidores y de los usuarios a nivel nacional, instituido por la Ley 30 de julio de 1998, n 281, la cual ha confluido en el Código de consumo (Dleg no 206/2005). Los deberes asignados por el legislador al Consejo tienen finalidades de contribución en el mejoramento y en la consolidación de la posición de consumidor/usuario en el mercado. El Consejo tiene su sede en el Ministerio del Desarollo Económico (Departamento para las empresas y la internacionalización - Dirección General para el Mercado, el Consumidor, la Vigilancia y la Normativa Técnica) y está dirigido por el Ministro o por

${ }^{45}$ Cfr. T.A.R. Campania Napoli, Sez. VI, Sent., 05-11-2014, n. 5671, Punto 5.1.3, en www.iusexplorer.it. 
su delegado. Hasta hoy, está compuesto por asociaciones de consumidores reconocidas según los criterios convenidos del árt. 137 del Código de consumo (Dleg 206/2005) y de un representante designado por la Conferencia unificada de que al árt. 8 del decreto legislativo 28 de agosto de 1997, n²81.

El Consejo invita a sus reuniones los representantes de las asociaciones de tutela ambiental reconocidas $\mathrm{y}$ de las asociaciones nacionales de las cooperativas de los consumidores. Además, puede invitar representantes de entes y organizaciones que tienen funciones de reglamentación del mercado, de categorías económicas y sociales interesadas, de públicas administraciones competentes, y además de expertos de las materias de interés.

Clarificado este punto, resulta evidente como el legislador distinga este organo representativo de los consumidores y de los usuarios como el organo que representa los intereses de los ciudadanos también.

\section{Una reflexiones críticas conclusivas sobre la democracia de los} usuarios.

En verdad, si la disciplina se dedica a la tutela de los ciudadanos en la esfera que atiende a la democracia y a sus representación en teoría, las personas sujetas a dar sus pareceres, tendrían que ser los representantes de los ciudadanos mismos en las instituciones, o sea los grupos parlamentarios o su proyección de los partidos políticos en las asambleas electivas.

El hecho de que los portadores de intereses contrapuestos a los del Estado se individuan en usuarios significa que el Estado mismo reconoce que los ciudadanos no tienen instrumentos suficientes para participar en la definición de los standard, en cuanto pueden exprimir sus voces sólo al final de la legisladura a través del ejercicio del voto. Instituciones de democracia directa, como la iniciativa popular o de referendum abrogatorio y la petición tienen, de hecho, muy poca eficacia, contribuyendo en delinear aquella concepción "estática" de ciudadano en Constitución de que se habló en precedencia.

Esta falta de instrumentos eficaces para el ciudadano era sopesada por las instituciones de democracia representativas gracias al trabajo de los partidos políticos a través de los grupos parlamentarios.

En conclusión, si la transparencia está al servicio de una mayor conciencia para los ciudadanos y, luego, de un mejor ejercicio de la democracia, habrá sido suficiente 
que la P.A. escuchara los representantes de los ciudadanos mismos, o sea el Parlamento. Desgraciadamente, en esta lógica se ha inserido la desconfianza de la sociedad civil para sus representantes en el Parlamento y esta se ha reflejado en la normativa. Por eso, para tutelar unos derechos de los ciudadanos, se ha preferido los representantes de las asociaciones de consumidores y de los usuarios más bien que los representante de los ciudadanos mismos.

Las asociaciones de los consumidores y de los usuarios llegan a ser partes institucionales también para finalidad de la categoría dogmática de los ciudadanos.

Por lo demás, desde la ley $n^{\circ}$ 146/90 (que lleva las normas de ejercicio del derecho de huelga en los servicios públicos esenciales y de la salvaguardia de los derechos de la persona constitucionalmente tutelados) se atribuían a las asociaciones de los usuarios muchos poderes con la finalidad de tutelar sus representantes. Entre los más considerables, hay la facultad de activar los procedimientos judiciales previstos por la Ley $\mathrm{n}^{\text {o }}$ 281de 1998, «también sólo con la finalidad de obtener la publicación, a expensas de responsable, de la sentencia que comprueba la violación de los derechos de los usuarios, o bien de pedir a la Comisión de Garantía la apertura de procedimientos de valutación del comportamiento de los promotores de la huelga (art. 4, 4-quater apartado); y además la posibilidad de exprimir su parecer sobre los acuerdos su las prestaciones indispensables antes de la valutación de idoneidad de la Comisión de garantía y sobre las propuestas de reglamentación provisional (árt. 13, 1 apartado, letra a). En última análisis, los poderes aportados a los usuarios eran ya auténtica "parte social", equiparada en la Ley n ${ }^{\circ} 146 / 90$, a los sindicatos.

Entonces, parece razonable pensar en un concepto de ciudadanía más "atécnico" y más "moderno", ya que, más nuestra sociedad ha llegado a ser "sociedad de sevicios", más la fruición de los servicios considerados “esenciales" incide en la participación de cada uno a la vida política, económica y social, en el desarrollo de propia personalidad: acaba con ser una de las condiciones de la efectividad de la ciudadanía de que el usuario es fuerte protagonista.

Por fin, las normas su la elevación del CNCU como parte institucional subrayan también como la relación entre Estado y ciudadano no es más oficialmente basada en valores de autoridad-sumisión como se ha visto supra. 
Esta situción actual que se impone como una ulterior forma de participación también política y que se entrelaza con la soberanía, sin embargo, no es acogida favorablemente por parte de la doctrina ${ }^{46}$.

En particular modo, es necesario detenerse en el antedicho "papel premonitorio al ejercicio de la soberanía", que tiene que ser visto con espíritu crítico. La acción de las asociaciones de los consumidores y usuarios, de hecho, no se lleva adelante a través de una dialéctica democrática en las instituciones parlamentarias que tienen que sintetizar los fuertes intereses, sino también a través de mecanismos de lobbying y de governance, «o sea afuera de los procedimientos constitucionales, donde sin embargo se encuentran con los intereses económicos organizados que desde hace tiempo allì se han instalado» ${ }^{47}$. Entonces, el lugar donde hoy la política se mueve es el "mercado" y el "movimiento de los consumidores ha llegado a ser la élite del informe y genérico conjunto de ciudadanos, élite que, se considera legitimada en reivindicar los derechos en el mercado y en actuar en este. Las imperfecciones del circuito democráticorepresentativo y su comprobada ineficiencia acreditan unas avanguardias en representar los intereses popular, y, en este, las organizaciones de los consumideores se encuentran normalmente aliadas a las asociaciones ambientales. El éxito de estas organizaciones nace por la crítica a la democracia representativa: éstas se presentan como avanguardias compuestas por personas legitimadas no por el voto, sino por la bondad y pureza de sus convinciones y por la promesa que lucharán para los ideales profesados sin abandono ni compromisos. Defienden "valores no negociables" como todos los fundamentalistas, y como todos los fundamentalistas presuponen y alimentan - conscientemente o no - una cultura antidemocrática, propio porque antipolítica» ${ }^{48}$.

\footnotetext{
${ }^{46}$ En este sentido, cfr. también LUCIANI, M., "Unità nazionale e struttura economica, Unità nazionale e struttura economica. La prospettiva della Costituzione repubblicana", relación al Congreso anual AIC en Costituzionalismo e Costituzione nella vicenda unitaria italiana, que hubo en Torino el 28 de octubre de 2011, en www.rivistaaic.it, p. 52, nt. 259 en que sostiene que aunque unas teorias sostengan que existe una verdadera "democracia de los consumidores" en cuanto estos orientan la producción y los precios a través de la demanda, (tutelados, por otra parte, por el árt. $41,2^{\circ}$ apartado, Const.), la misma no puede sustituir la "democracia de los ciudadanos". Del concepto de "democracia de los consumidores" v. EINAUDI, L., "La civitas humana di Wilhelm Röpke", Riv. di storia econ., 1942 - con el título "Economia di concorrenza e capitalismo storico. La terza via fra i secoli XVIII e XIX" -, ahora en FORTE, F., y FELICE, F., (a cura di), "Il liberalismo delle regole, Genesi ed eredità dell'economia sociale di mercato", Soveria Mannelli, Rubbettino, 2010, p. 225.

${ }^{47}$ BIN, R., "I diritti di chi non consuma", relación al Congreso "Diritti dell'individuo e diritti del consumatore" - Milano, 14 de diciembre de 2007, en www.robertobin.it y en www.forumcostituzionale, p. $2 \mathrm{~s}$.

${ }^{48}$ BIN, R., "I diritti di chi non consuma", cit., p. 2 que se basa su las observaciones del sociólogo FUREDI, F., "Consuming Democracy: activism, elitism and political apathy", en www.geser.net/furedi.html.
} 
Se puede también encontrar este aspecto en relación al "papel sancionatorio" 49 de los derechos de los consumidores, o sea en el momento en que han realizado las class actions para perseguir finalidad atinentes al circuito ciudadanía-representancia como en el caso de la tasación. Es evidente la «emarginación de los órganos políticos» ${ }^{50}$ en favor de los judiciarios empleados como lugar preferido por los consumidores y usuarios para ver tutelados unos derechos que antes "administraba" de manera preventiva el Parlamento. Los sociólogos han estigmatizado el hecho que los movimientos de los consumidores representan un indicio de la crescente desconfianza en la política: «no hay dudas que el crecimiento de los movimientos de los consumideores va a la par con la decadencia de las formas tradicionales de empeño social y partecipación política» ${ }^{51}$. Y además, «si no queda nunca más que hacer, es probable que los ciudadanos dejen completamente la idea de colectividad y de sociedad democrática para encomendarse al mercado y, quiero añadir, a su propias calidades y iniciativas de consumidores para dirimir las controversias» 52 .

Es en este sentido que se está produciendo la última mutación de las formas del estado, concebida según el perfil de investigación de la manera de configurar las relaciones entre gobernantes y gobernados en torno a la formación de la orientación política. $^{53}$

Se asiste, por eso, al "populismo de mercado" "54, o sea a la concepción que sólo en éste se encuentre libertad de elección y, luego, democracia. «En controtendencia con respecto al principio que ha sido una guía para la época moderna, o sea la expansión de la participación política, el "populismo de mercado" proclama la política enemigo

\footnotetext{
${ }^{49}$ Cfr. CERIONI, M., "Diritti dei consumatori e degli utenti”, cit., passim.

${ }^{50}$ LAMARQUE, E., “L'attuazione giudiziaria dei diritti costituzionali”, Quad. cost., 2008, p. 269.

${ }^{51}$ FUREDI, F., op. cit., s.p.

52 LAWSON, N., "Dare More Democracy", London, The Compass, 2006, p. 18. Entre parentesis cuadras hay una añadidura hecha por BAUMAN, Z., "Homo Consumens. Lo sciame inquieto dei consumatori e la miseria degli esclusi", edizioni Erickson, Gardolo (Trento), 2007, p. 38.

${ }^{53}$ En este sentido, BIN, R., op. cit., 3, nonché CERIONI, M., "Diritti dei consumatori e degli utenti", cit., passim.

${ }^{54}$ FRANK, T., "Marché de droit divin: capitalisme sauvage et populisme de marché », Marseille, Agone, 2003.
} 
número uno de la democracia y considera, en cambio, el mercado como el instrumento democrático más fiable (si non totalmente el único posible)» ${ }^{55}$.

También en aquella amplísima porción de mercado, que antes había sido dejada en mano de entes locales o de organizaciones públicas, estan vigentes las mismas reglas. El usuario se ha sustituido al ciudadano porque sólo el primero puede ensalzar unos instrumentos de control eficaces (customer satisfaction, cartas de los servicios, class action contra de la p.a., autoridad administrativas independientes y etc.) mientras el circuito ciudadanía-representatividad ha sido quitado de las posibilidades de control, en cuanto los consejos comunales o provinciales no administran directamente los servicios atribuidos a sociedades privadas (en que sólo en pocos casos ha participado también de entes públicos que, sin embargo, por sus números elevatos, no están en las condiciones para poder ejercitar sus control tradicional) ${ }^{56}$.

En conclusión, es pertinente recordar el pensamiento del estudioso más crítico del consumerism en relación a los proceso democráticos, el cual nos pone en guardia del hecho que «en este momento, no existe un método alternativo a la democracia y a la participación democrática y en cada caso el mercado y los movimientos de los consumidores no pueden sostituirlos porque son ellos mismos indicios de la caída del empeño político y de la confianza en la acción política y en la autoridad del Estado en la vida pública. Son signales de rendición por parte de los ciudadanos» ${ }^{57}$.

Sin embargo, se debe evidenciar que la exosmosis entre ciudadano y usuario y la elevación del CNCU como parte institucional van acogidas de manera positiva en la

55 BAUMAN, Z., "Homo Consumens. Lo sciame inquieto dei consumatori e la miseria degli esclusi", edizioni Erickson, Gardolo (Trento), 2007, p. 39.

${ }^{56}$ En el mismo sentido v. BIN, R., op. cit., 5-6 que afirma que «la privatización de los servicios públicos permite de imaginarse a una gestión de dimensiones más amplia, mejor estructurada, más competitiva como justamente observa Merusi, los Comunes generalmente no tienen una dimensión de mercado. La entrada del capital privado y la unión de cultura managerial de empresa tienen, luego, un precio, o sea lo de la pérdida del control democrático. Enfrente a un servicio que por calidad y dimensión de la gestión no corresponde más a las dimensiones y a las reglas del ente representativo, quién ejercita los controles? Nunca más los ciudadanos, a través del circuito representativo, sino los usuarios. El consejo comunal y su obsoleto equipaje de instrumentos tradicionales (la interrogación, la interpelación, la encuesta) han sido sustituidos por la customer satisfaction, la proximidad política del ente a los ciudadanos por la proximidad psicológica del administrator al usuario: la protesta política contra los deservicios se derrite en un call center. En vez de la viejas y austeras municipalizadas, la publicidad resplandeciente nos monstra la imágen cautivadora del administrador privado y la figura atrayente de la top model que acoje el público, ya que la satisfacción del usuario - nos enseñan los manuales de estrategia empresarial - se mesura a través de la calidad percibida del servicio y no su la efectiva. Aquí hay la sustitución del ciudadano por el usuario». En el gigantismo de los servicios públicos, v. el ejemplo del mismo A. en Hera Modena (p. 7)

${ }^{57}$ BAUMAN, Z., op. cit., 42. 
misura de que se entiendan no como sustitutivas del concepto de ciudadano, sino adicionales, en cuanto atribuyen a éste unas facultades y unos poderes ulteriores, dinámicos que el ciudadano "estático" no tenía. En suma, la figura del usuario es la respuesta en términos de resiliencia del ciudadano al poder del Estado entendido como suministrador de servicios, también políticos. Como si un arquero (ciudadano) en final viniera dotado de arco y flechas (gracias a la relación de usuario) para arrojar defendiendose de la autoridad estatal. 